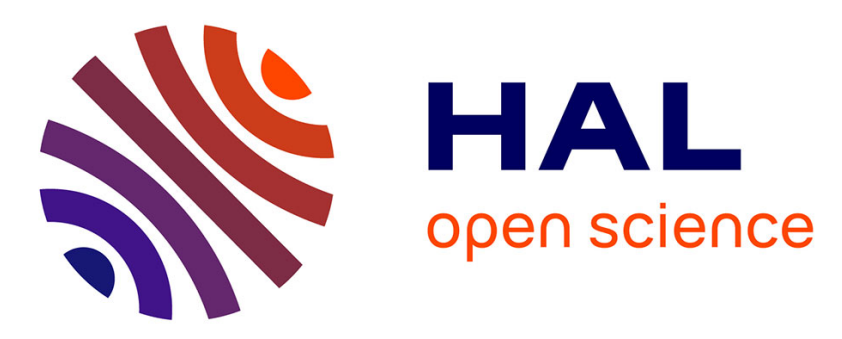

\title{
Assessing functional and structural cardiotoxicity in cultured human iPSC-cardiomyocytes in a single plate format
}

Liang Guo, Mike Furniss, Levy Batista, Thierry Bastogne, Yan Zhuge, Joseph Wu, Sandy Eldridge, Myrtle Davis

\section{To cite this version:}

Liang Guo, Mike Furniss, Levy Batista, Thierry Bastogne, Yan Zhuge, et al.. Assessing functional and structural cardiotoxicity in cultured human iPSC-cardiomyocytes in a single plate format. Safety Pharmacology Society 2017 Annual Meeting, SPS 2017, Sep 2017, Berlin, Germany. hal-01669498

\section{HAL Id: hal-01669498 https://hal.science/hal-01669498}

Submitted on 20 Dec 2017

HAL is a multi-disciplinary open access archive for the deposit and dissemination of scientific research documents, whether they are published or not. The documents may come from teaching and research institutions in France or abroad, or from public or private research centers.
L'archive ouverte pluridisciplinaire $\mathbf{H A L}$, est destinée au dépôt et à la diffusion de documents scientifiques de niveau recherche, publiés ou non, émanant des établissements d'enseignement et de recherche français ou étrangers, des laboratoires publics ou privés. 


\title{
Assessing functional and structural cardiotoxicity in cultured human IPSC-cardiomyocytes in a single plate format
}

\author{
L. Guo, M. Furniss, J. Hamre, L. Batista*, T. Bastogne*, Y. Zhuge\#, J.C. Wu\#, S. Eldridge ${ }^{\dagger}$, M. Davis ${ }^{\dagger}$
}

Laboratory of Investigative Toxicology, Frederick National Laboratory for Cancer Research/Leidos Biomedical Research, Inc.,

Frederick, MD 21702; *University of Lorraine, INRIA, Vandœuvre-lès-Nancy, France

\#Stanford Cardiovascular Institute, Stanford University, Stanford, CA 94305

tDCTD, National Cancer Institute, Bethesda, MD 20892

\section{Abstract}

A comprehensive profiling of cardiotoxicity early in drug discovery and A evelopment can aid in reducing late-stage attrition and establishing riskpatoms and instumentspecifed phete formts are requied for this type of

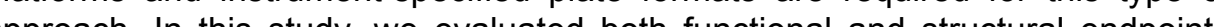
associted with cardiotoxicity in human induced pluripotent stem cellderived cardiomycytes (hipSC.CM) cultured in a single 384-well phate. We meatied

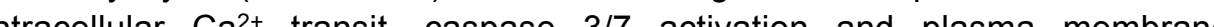

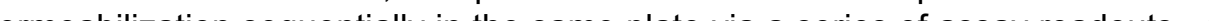

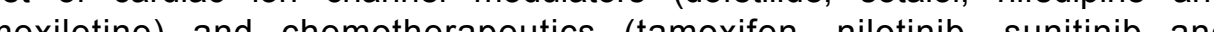
doxorbicin) was tested at clinically reterate con, (intracellur $\mathrm{Ca}^{2+}$ transits after a short-erm (30 minutes) exposure, and phasm

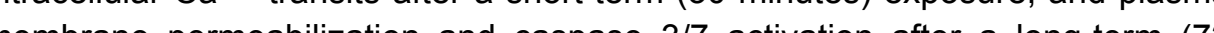

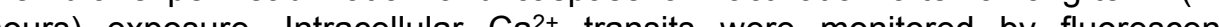

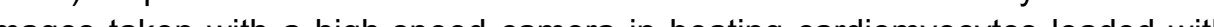
Cages taken wh lithigh speed cam Was ide

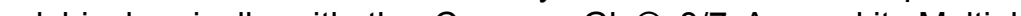

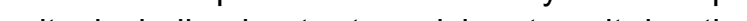
(CTD) mas de (III) alon WIn CTD the CTD a Dither Ca2+cycling and arrhythmogenicity. Increases in postive nuclear staining for

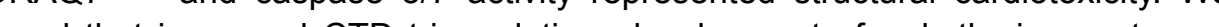
found that increased CTD trangulation, development of anhylimic events and bethe

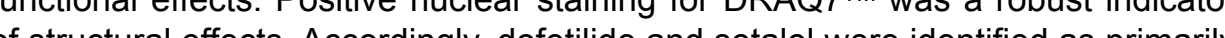

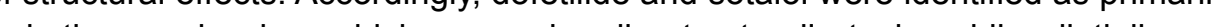
arrhythmogenic, doxorubicin was primarily structurally toxic, while nilotinib and sunitinib were both arrhylhmogenic and structurally toxic. The use of these endpoints in a single plate format simplifies the card
Results

$\mathrm{Ca}^{2+}$ transits of beating cardiomyocytes:

Figure 1. $\mathrm{Ca}^{2+}$ cycling imaged at $51 \mathrm{fps}$ from a single view-field
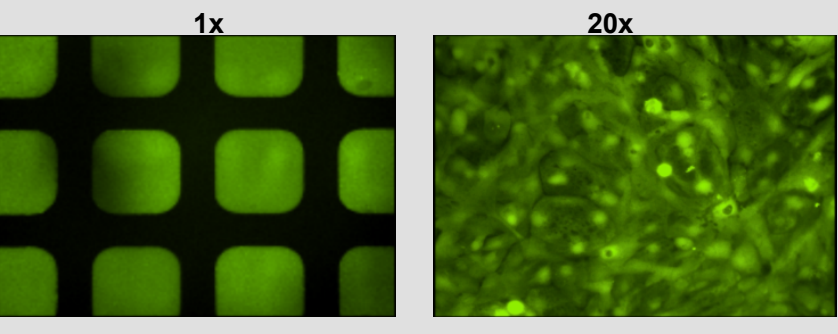

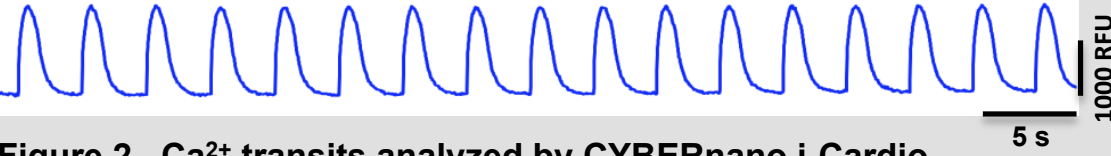

Figure 2. $\mathrm{Ca}^{2+}$ transits analyzed by CYBERnano i-Cardio

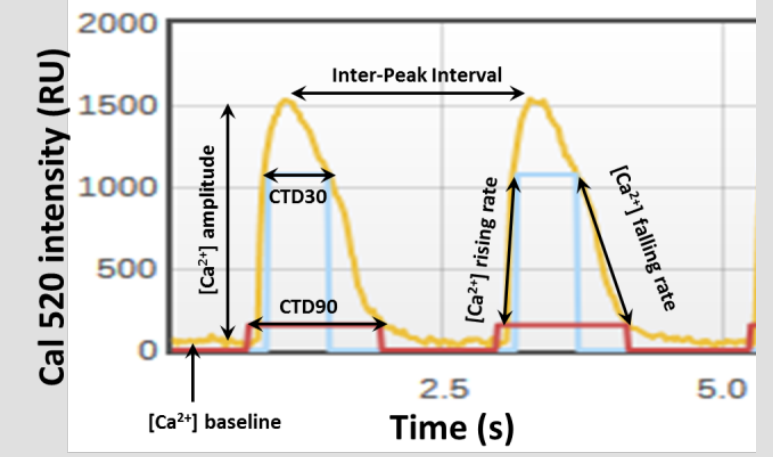

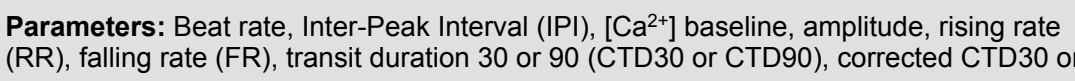
90 by $\mid$ PI $(C T D c=C T D(n) / P(n-1)$ : Triangulation index: $=$ CTD9o/CTD30

Figure 3. Representative traces of typical effects on $\mathrm{Ca}^{2+}$ transits

Pre-dose

CTD prolongation/decreased beat rate

\section{Introduction}

Cardiotoxicity is frequently a dose-limiting toxicity associated with many highly efficacious chemotherapeutics that include both classic cytotoxic or cytostatic agents, such as doxorubicin or other anthracycline analogs, and newly developed targeted anti-cancer molecules such as protein kinase inhibitors (i.e. sunitinib, dasatinib and nilotinib). As this adverse effect can be manifested by either structural damage (i.e.
cardiomyopathy and heart failure) or functional alteration (i.e. arrhythmia cardiomyopathy and heart failure) or functional alteration (i.e. arrhythmia and functional cardiotoxicity should be included in preclinical safety profiling of each new anti-cancer drug prior to the first dose in human.

Human induced pluripotent stem cell-derived cardiomyocytes (hiPSCCMs) represent a novel cellular model system to test for cardiotoxicity and are being used increasingly with a wide variety of analytic platforms in study of cardiac biology and drug safety testing. In this study, we developed an image-based, multiplex assay that enables interrogation of both functional and structural toxicity endpoints in a single plate

\section{Methods \& Materials}

Cells:

Cryopreserved iPSC-cardiomyocytes were provided by Dr. Joseph C.

Wu and Stanford Cardiovascular Institute (SCVI) Biobank

Reagents:

RPMI 1640, BD Matrigel (Fisher/Corning); B27-insulin, DMEM/F12 (Gibco/Life Science); Accutase (Sigma); Cal-520 ${ }^{\circledR} \mathrm{Ca}^{2+}$ dye (AAT Bioquest), DRAQ7M DNA dye (abcam), Caspase-Glo 3/7assay kit sunitinib and doxorubicin (NCl Compound Repository)

Biomarkers:

$\mathrm{Ca}^{2+}$ transits: contractile function, repolarization-delay, arrhythmia

DNA stain: permeabilization of plasma membrane (cell death)

Caspase 3/7 activity: apoptosis activation

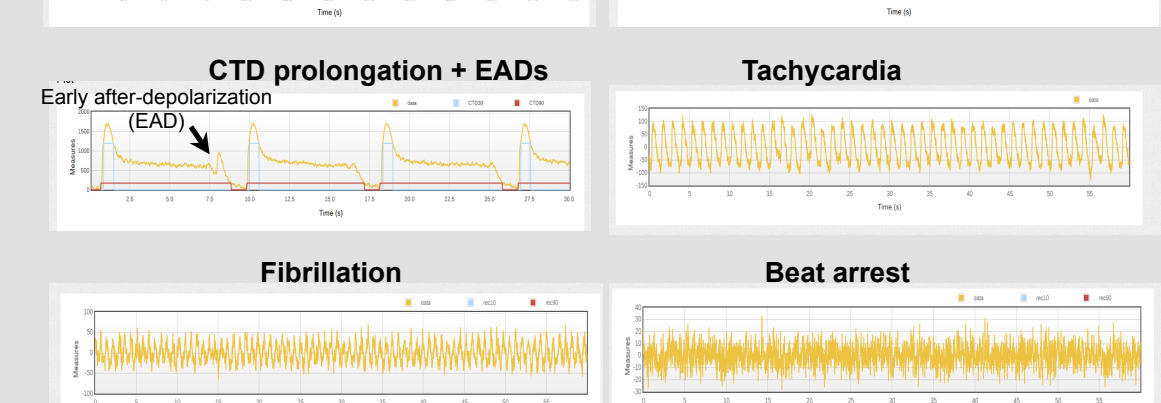

Table 1. Summary of effects on $\mathrm{Ca}^{2+}$ transit parameters

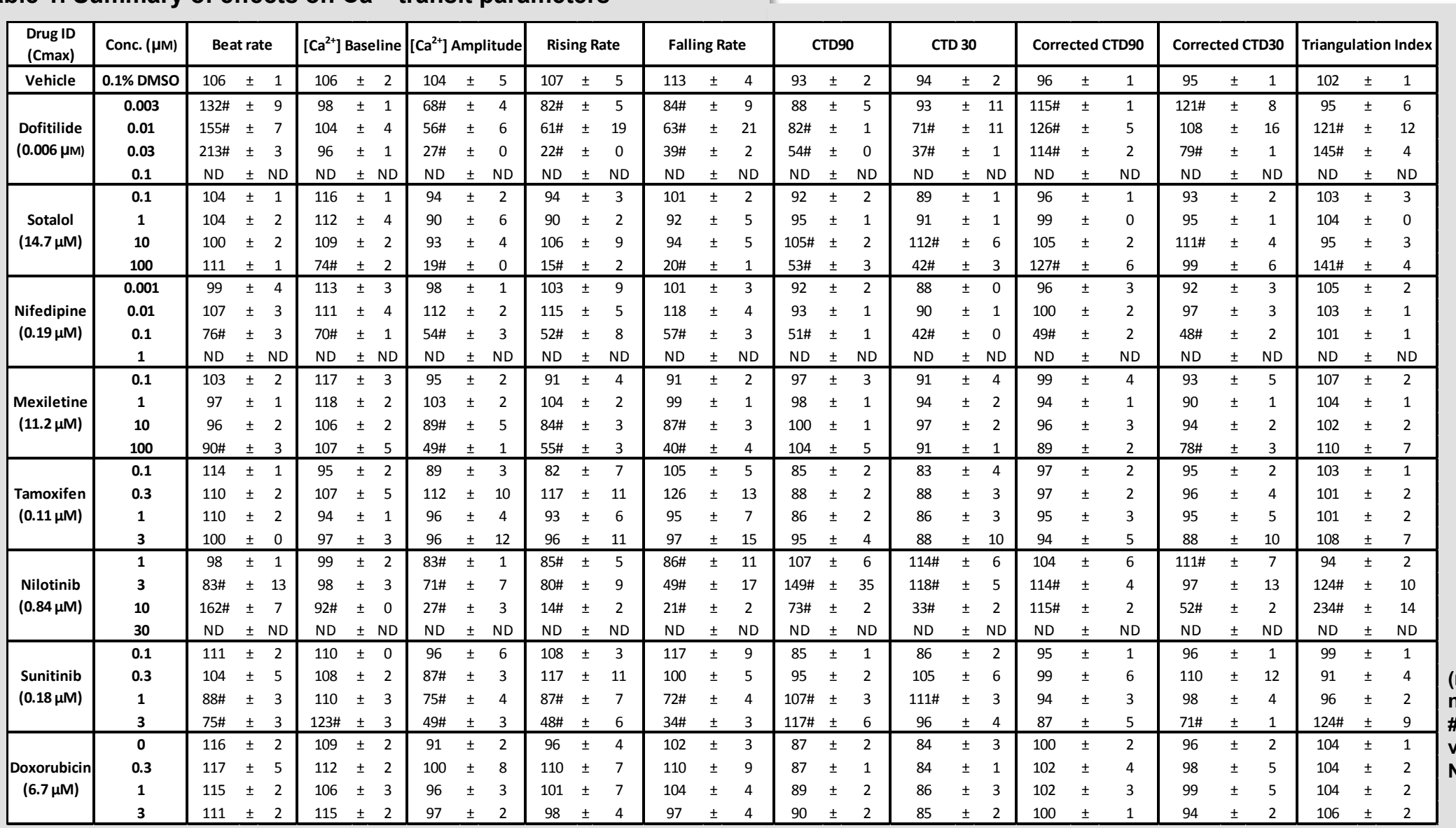

Figure 4. Beat variability analysis on Poincaré plots of CTD90

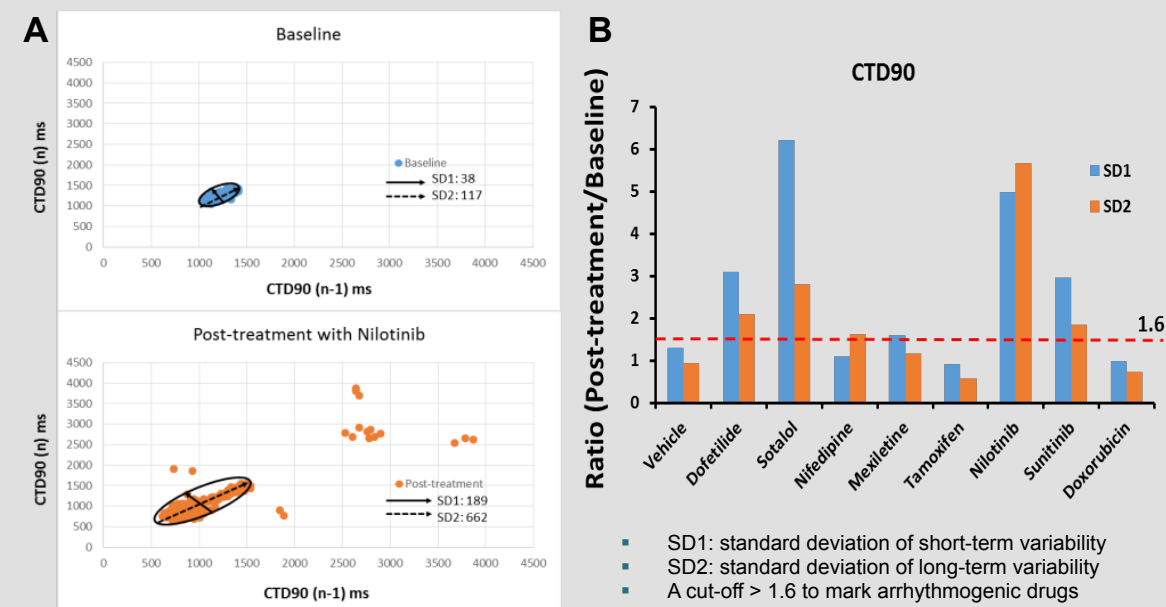

Permeabilization of plasma membrane Figure 5. Representative images of nuclear stains
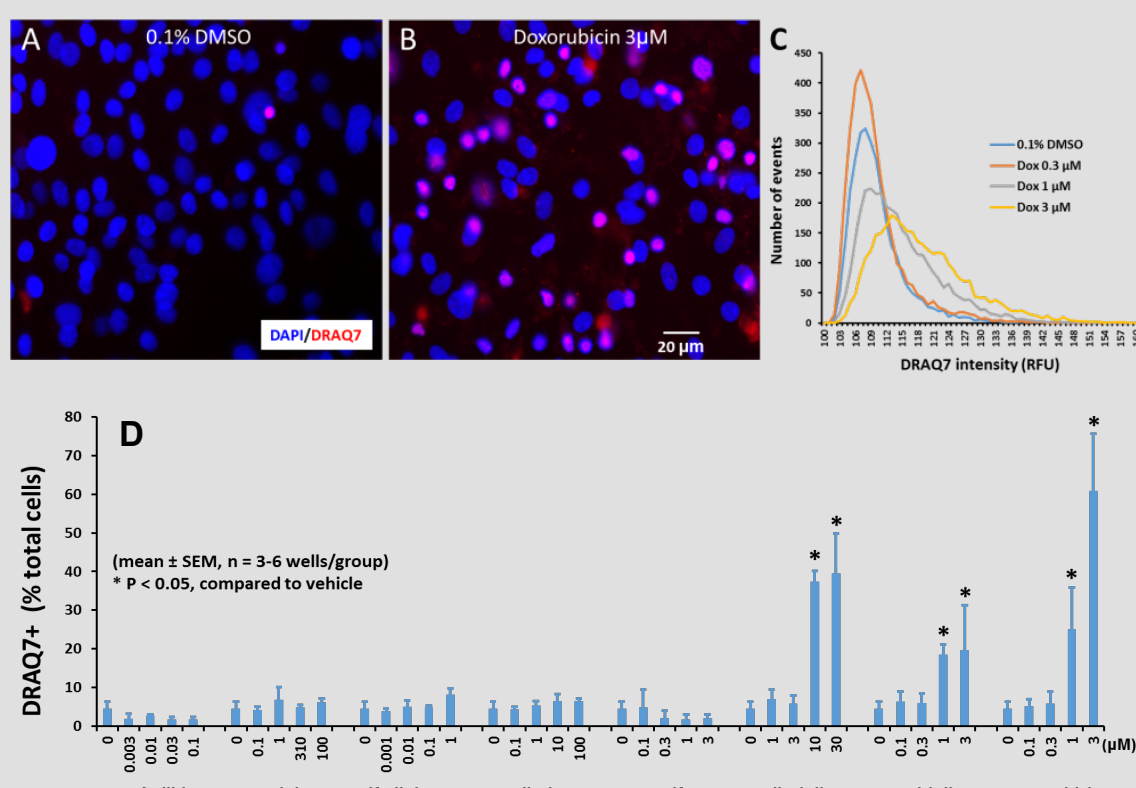

Activation of apoptosis

Figure 6. Caspase $3 / 7$ activity

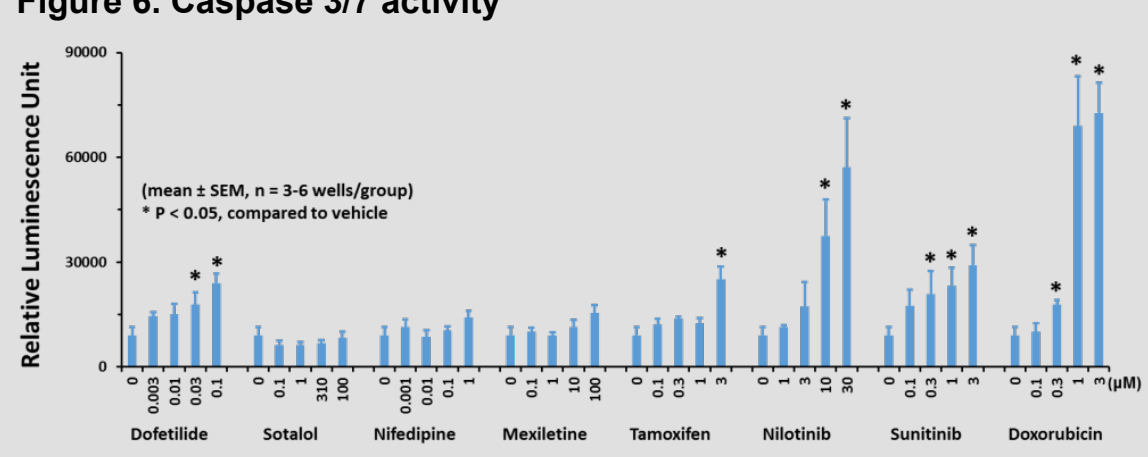

Workflow:

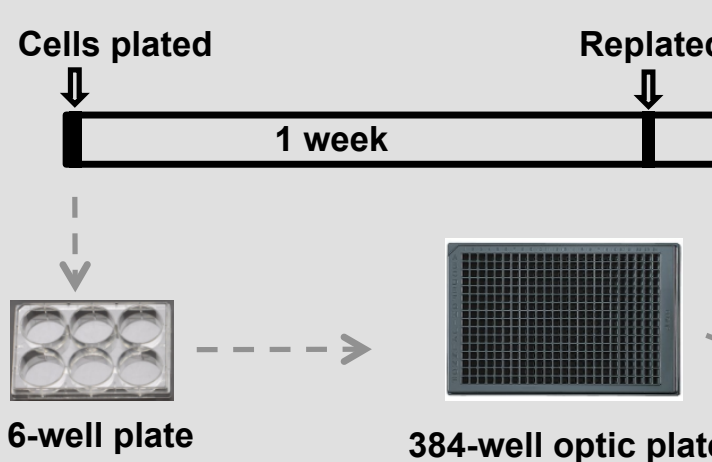

Data analysis:

Measurement of beat-to-beat $\mathrm{Ca}^{2+}$ transits was performed by CYBERnano $\mathrm{i}$-Cardio platform; treatment-related changes in each endpoint were shown as \% of the baseline value. Cells stained positive with DRAQ7 were shown as \% of total nuclear (DAPI) counts and Caspase 3/7 activity was quantified as the luminescence intensity in each well. Statistic analysis was conducted with Student's $t$-test.
Assays for $\mathrm{Ca}^{2+}$ transit DNA stain + Caspase 3/7 1 week $\quad 30 \mathrm{~min}$ and $72 \mathrm{hrs}$

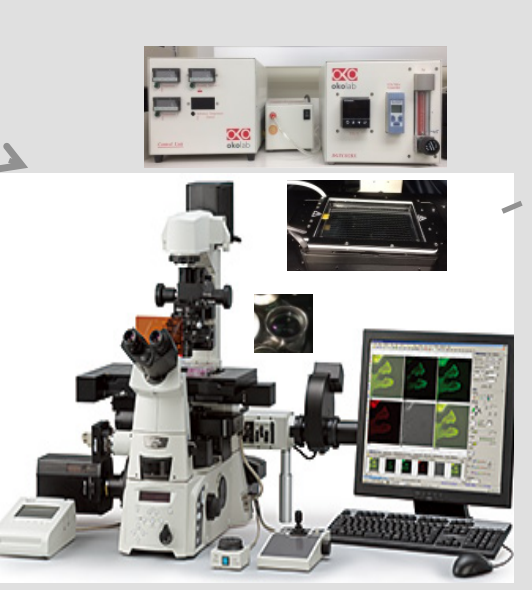

Nikon Eclipse Ti Fluorescence Microscope
Discussion \& Conclusion

$\square \mathrm{Ca}^{2+}$ transits were sensitive to ion channel modulators, with changes in beat rate and $\mathrm{Ca}^{2+}$ transit amplitude; EADs, beat-to-beat variability and triangulation of CTD were more specific than CTD lengthening to predict arrhythmogenesis

Caspase 3/7 activity was a sensitive indicator of insults to hiPSC-CMs but increased nuclear stains of impermeable DNA dye was more robust to label structural cardiotoxicity
IN-Cell Analyzer (HCA)

Acknowes: The author thanks Drs. Palph Parchment and Jerry Collins for magat support. This project has been funded in whole or in part with federal funds from the Nation

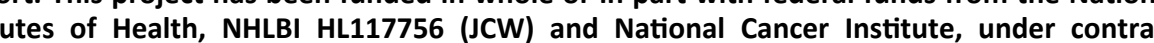
HHSN261200800001E. The content of this publication does not necessarily reflect the views or policies of the Department of Health and Human Services, nor does mention of tra
commercial products, or organizations imply endorsement by the U.S. Government.

DEPARTMENT OF HEALTH AND HUMAN SERVICES • National Institutes of Heath • National Cancer Instite 